\title{
Parameters That Influence Buckling Forces of a Fully Embedded Pile Based on the Finite Difference Method
}

\author{
Vlora Shatri ${ }^{1}$, Luljeta Bozo ${ }^{2}$, Bajram Shefkiu ${ }^{1}$ and Burbuqe Shatri ${ }^{1}$ \\ 1. Department of Civil Engineering, Faculty of Civil Engineering and Architecture, University of Pristina, Pristina 10000, Kosovo; \\ 2. Department of Urban Planning and Environment Management, University of Polis, Tirana 1005, Albania
}

\begin{abstract}
This paper work aims to present the effect of the soil stiffness $(k)$, boundary conditions of piles and embedded length of piles $(L)$ on a buckling force of a fully embedded pile and subject to an axial compression force only, based on the finite difference method. Based on this method, MATLAB software is used to calculate the buckling forces of piles. Effect of the soil stiffness $(k)$, boundary conditions of piles and embedded length of piles $(L)$ on a buckling force have been studied for reinforced concrete pile, whereas the modulus of horizontal subgrade reaction is adopted constantly with depth, increasing linearly with depth with zero value at the surface and increasing linearly with depth with nonzero value at the surface.
\end{abstract}

Key words: Finite difference method, pile, pile buckling force, buckling modal shapes.

\section{Introduction}

"Buckling" phenomena, by many authors is described as an unsustainability of an ideally straight column subject to an axial force exceeding a certain value.

Bifurcation is a field of linear analysis where determination of critical force of an ideal system is based on a solution of a standard problem of eigen value. The smallest eigen value determines the level of load up to which the system - the pile is stable, where as the respective eigen vector represents an equilibrium type of a pile.

Aiming to calculate the response of a vertical pile fully embedded on ground and subject to an external axial force, the pile shall be treated as a beam of an elastic foundation.

\section{Buckling Force of a Fully Embedded Pile According to Finite Difference Method}

Equation of the buckled pile subject to an axial load is:

Corresponding author: Burbuqe Shatri, Ph.D.; research fields: structural engineering. E-mail: bshatri@gmail.com.

$$
E \cdot I \cdot \frac{d^{4} y}{d x^{4}}+P \cdot \frac{d^{2} y}{d x^{2}}+k_{h} \cdot y=0
$$

where:

$E I$ - pile stiffness;

$P$ - pile axial force;

$k_{h}=k_{0}+n_{h} \cdot x$-modulus of horizontal subgrade reaction approach by Ref. [4];

$n_{h}$ - constant of horizontal subgrade reaction.

Based on the finite difference method, the solution of Eq. (1) can be obtained using the differential formulae. This method is a numerical technique that is used to solve the differential equations determining so the approximate solution only and the derivative of a function at a certain point may be approximated with an algebraic expression consisting of the values of that function in that point as well as of several adjacent points, meaning that through this method, the differential equation is transformed into an algebraic equation. The application of this method in solving buckling of piles has been discussed in Refs. [1, 3].

If the pile is divided into $n$ nodes $(1,2,3, \ldots, m-1$, $m+1, \ldots, n)$, and $n-1$ equal segments, Fig. 1 , then based on the finite difference method, for the point $\mathrm{m}$ of the pile the following could be written: 


$$
\begin{gathered}
P\left(\frac{d^{2} y}{d x^{2}}\right)_{m}=\left[P\left(y_{m-1}-2 y_{m}+y_{m+1}\right)\right] \frac{1}{h^{2}} \\
\left(\frac{d^{2} M}{d x^{2}}\right)_{m}=\left[\begin{array}{l}
y_{m-2} E_{m-1} I_{m-1}+ \\
y_{m-1}\left(-2 E_{m} I_{m}-2 E_{m-1} I_{m-1}\right)+ \\
y_{m}\left(4 E_{m} I_{m}+E_{m-1} I_{m-1}+E_{m+1} I_{m+1}\right)+ \\
+y_{m+1}\left(-2 E_{m} I_{m}-2 E_{m+1} I_{m+1}\right) \\
+y_{m+2} E_{m+1} I_{m+1}
\end{array}\right] \frac{1}{h^{4}}(3)
\end{gathered}
$$

For a certain point $m, n_{h}$ may be expressed as $n_{h}: x=$ $n_{h} \cdot(m-1) \cdot h$, where $n$ is the number of the nodes on a pile, $h=L /(n-1)$ and $P$ are considered to be constant along the entire pile length $L$, than the Eq. (1) based on the finite difference method may be formulated as follows:

$$
\begin{gathered}
y_{m-2} E_{m-1} I_{m-1}+ \\
+y_{m-1}\left(P h^{2}-2 E_{m} I_{m}-2 E_{m-1} I_{m-1}\right)+ \\
+y_{m}\left(\begin{array}{l}
4 E_{m} I_{m}+E_{m-1} I_{m-1}+ \\
E_{m+1} I_{m+1}-2 P h^{2}+k_{0} h^{4}+n_{h}(m-1) h^{5}
\end{array}\right)+ \\
+y_{m+1}\left(-2 E_{m} I_{m}-2 E_{m+1} I_{m+1}+P h^{2}\right)+ \\
+y_{m+2} E_{m+1} I_{m+1}=0
\end{gathered}
$$

If adopted along the pile length, $E_{m} I_{m}=E_{m-1} I_{m-1}=$ $E_{m+1} I_{m+1}=E I$, then Eq. (4) will become of this form:

$$
\begin{aligned}
& E I\left(y_{m-2}-4 y_{m-1}+6 y_{m}-4 y_{m+1}+y_{m+2}\right)+ \\
& P h^{2}\left(y_{m-1}-2 y_{m}+y_{m+1}\right)+ \\
& k_{0} h^{4} y_{m}+n_{h}(m-1) h^{5} y_{m}=0
\end{aligned}
$$

where, $y_{m}$ is the lateral displacement of the node $m$. Eq. (5) may be written as follows:

$$
\begin{aligned}
& \frac{P \cdot L^{2}}{E I \cdot(n-1)^{2}}\left(y_{m-1}-2 y_{m}+y_{m+1}\right)=y_{m-2}-4 y_{m-1}+ \\
& +\left(6+\frac{k_{h m} \cdot L^{4}}{E I \cdot(n-1)^{4}}+\frac{n_{h} \cdot L^{5} \cdot(m-1)}{E I \cdot(n-1)^{5}}\right) y_{m}- \\
& -4 y_{m+1}+y_{m+2}
\end{aligned}
$$

For the nodes from 1 to $n$, as the divisions on a pile, $n$-equations may be formulated. To resolve these $n$-equations, four additional equations are deemed necessary that means that " $n+4$ " equations are required in total. These four equations represent the two end restrain conditions at the tip and at the top of a pile.

The boundary conditions of the head of the pile based on the finite difference method may be expressed as follows [5]:

If the horizontal displacement at the pile head is limited,

$$
y_{0}=0
$$

If the rotation is limited,

$$
\left(\frac{d y}{d x}\right)_{x=0}=0 \Rightarrow \frac{y_{1}-y_{-1}}{2 h}=0 \Rightarrow y_{1}-y_{-1}=0
$$

If the pile head is released from horizontal restraining, then the shear force perpendicular to the axis of the pile will be totally balanced with transverse component of the axial force $P$ applied as follows:

$$
\begin{gathered}
(V)_{x=0}+P(\theta)_{x=0}=0 \Rightarrow E I\left(\frac{d^{3} y}{d x^{3}}\right)_{x=0}+P\left(\frac{d y}{d x}\right)_{x=0}=0 \\
\Rightarrow E I \frac{y_{2}-2 y_{1}+2 y_{-1}-y_{-2}}{2 h^{3}}+P \frac{y_{1}-y_{-1}}{2 h}=0 \\
\Rightarrow\left(y_{2}-2 y_{1}+2 y_{-1}-y_{-2}\right)+\frac{P L^{2}}{E I(n-1)^{2}}\left(y_{1}-y_{-1}\right)=0
\end{gathered}
$$

If the pile head is released from the restrain in rotation then the moment is zero,

$$
\begin{gathered}
M=E I\left(\frac{d^{2} y}{d x^{2}}\right)_{x=0}=0 \Rightarrow E I \frac{y_{1}-2 y_{0}+y_{-1}}{h^{2}}=0 \\
\Rightarrow y_{1}-2 y_{0}+y_{-1}=0
\end{gathered}
$$

For the spring support of stiffness $k_{v}$ with the possibility of horizontal displacement:

$$
\begin{gathered}
(V)_{x=0}+P(\theta)_{x=0}=k_{v} \cdot y \Rightarrow \\
E I \cdot\left(\frac{d^{3} y}{d x^{3}}\right)_{x=0}+P \cdot\left(\frac{d y}{d x}\right)_{x=0}=k_{v} \cdot y \\
\Rightarrow \frac{E I}{P \cdot L^{2}} n^{2} \cdot\left(y_{2}-2 y_{1}+2 y_{-1}-y_{-2}\right)+ \\
+\left(y_{1}-y_{-1}\right)-\frac{k_{v} \cdot L}{P \cdot n} y_{0}=0
\end{gathered}
$$

For the spring support of stiffness $k_{\Theta}$ with the possibility to rotate: 


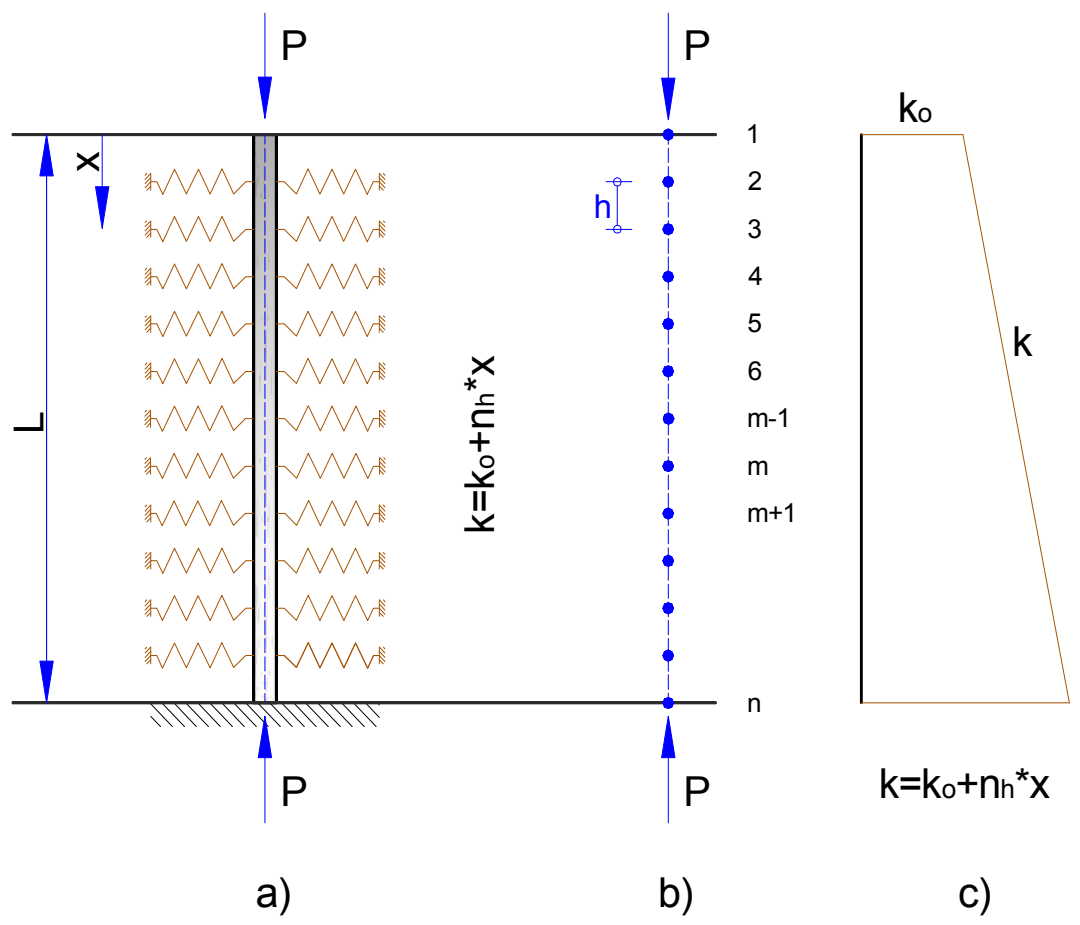

Fig. 1 Model of a pile based on the method of finite differences: (a) a pile pinned at the tip and pinned at the top (p-p); (b) division of the pile in " $n$ " nodes; (c) modulus of horizontal subgrade reactions $k=k_{0}+n_{h}: x$.

$$
\begin{array}{r}
M=E I \cdot\left(\frac{d^{2} y}{d x^{2}}\right)_{x=0}=k_{\theta} \cdot\left(\frac{d y}{d x}\right)_{x=0}=0 \\
\Rightarrow \frac{E I}{k_{\theta} \cdot L}\left(y_{1}-2 y_{0}-y_{-1}\right)-\left(y_{1}-y_{-1}\right)=0
\end{array}
$$

Then Eq. (6) written for each and every node of a pile together with four equations of the boundary conditions of a pile, may be expressed in matrix shape and as follows:

$$
[\boldsymbol{A}]\{y\}+\frac{P \cdot L^{2}}{E I \cdot(n-1)^{2}}[\boldsymbol{B}]\{y\}=0
$$

Eq. (13) may be written as follows:

$$
[\boldsymbol{A}]\{y\}+\lambda[\boldsymbol{B}]\{y\}=0
$$

For calculation of the buckling force of the pile, the problem is turned into a problem for calculating the eigen values of matrix equation:

$$
[\boldsymbol{A}+\lambda \boldsymbol{B}]=0
$$

Therefore, $\operatorname{det}|\boldsymbol{A}+\boldsymbol{\lambda} \boldsymbol{B}|=0$ can be used to determine $\lambda$. The eigen values of the problem are:

$$
\lambda=\frac{P L^{2}}{E I(n-1)^{2}}
$$

These eigen values may be determined through various mathematical software. In this paper, all calculations are done with the software MATLAB. Critical buckling force of a pile will be the one of the lowest value:

$$
P_{k}=\lambda \cdot E I \cdot(n-1)^{2} / L^{2}
$$

To determine the buckling length of the pile, the Euler's force for the pile of elastic material, $P_{E}$, is equated with the critical buckling force of the pile:

$$
\begin{gathered}
\pi^{2} E I /(\alpha L)^{2}=\lambda \cdot E I \cdot(n-1)^{2} / L^{2} \\
\alpha=\pi / \sqrt{\lambda} \cdot(n-1)
\end{gathered}
$$

where:

$\alpha$-the ratio between the equivalent buckling length of the pile, $L_{0}$ and the pile length, $L$.

2.1 Buckling Force of a Fully Embedded Pile, Pinned at the Head and Pinned at the Tip (p-p)

For cases considered in this paper, a reinforced 
concrete pile of a diameter $D=0.3 \mathrm{~m}$ and concrete class $\mathrm{C} 25 / 30$ is adopted. A constant axial load along the pile length is assumed and the initially straight pile axis.

The members of the matrixes $[\boldsymbol{A}]$ and $[\boldsymbol{B}]$ based on the finite difference method [6], for the case of fully embedded pile, pinned at the head and pinned at the tip (p-p) and a linear variation of soil stiffness, $k=k_{\mathrm{o}}$ $+n_{h} \cdot x$, (Fig. 1) (as by the software MATLAB) are:

Number of segments

for $(n-1)$

$\boldsymbol{A}=\operatorname{zeros}(n+4, n+4)$;

$A(1,3)=1$;

$\boldsymbol{A}(2,2)=1 ; \boldsymbol{A}(2,3)=-2 ; \boldsymbol{A}(2,4)=1$

$\boldsymbol{A}(n+3, n+3)=1 ; \boldsymbol{A}(n+3, n+2)=-2 ; \boldsymbol{A}(n+3$, $n+1)=1$;

$A(n+4, n+2)=1$;

for $i=1: n$

$A(\mathrm{i}+2, \mathrm{i}+2-2)=1 ; \boldsymbol{A}(i+2, i+2-1)=-4$;

$\boldsymbol{A}(\mathrm{i}+2, \mathrm{i}+2-0)=6+\left(k_{0}^{*} L^{\wedge} 4\right) /\left(E^{*} I^{*}(n-1)^{\wedge} 4\right)+$ $\left(n_{h}{ }^{*} L^{\wedge} 5^{*}(i-1)\right) /\left(E^{*} I^{*}(n-1)^{\wedge} 5\right) ; \boldsymbol{A}(i+2, i+2+1)=$ $-4 ; A(\mathrm{i}+2, \mathrm{i}+2+2)=1$

end

$\boldsymbol{B}=\operatorname{zeros}(n+4, n+4)$;

for $i=1: n$

$\boldsymbol{B}(\mathrm{i}+2, \mathrm{i}+2-1)=1 ; \boldsymbol{B}(\mathrm{i}+2, \mathrm{i}+2-0)=-2 ; \boldsymbol{B}(\mathrm{i}$
$+2, \mathrm{i}+2+1)=1$;

end

In Fig. 2, the relationship between the buckling force of a pile (p-p) and its length $(L)$ is given, for the case when modulus of horizontal subgrade reaction is constant along the pile length, $k_{h}=k_{0}=1,000 \mathrm{kN} / \mathrm{m}^{2}$. The pile (p-p) is deformed in a form of half a wave of a sine curve, of a number of waves dependent on the total pile length. With an increase of the pile length $(L)$, the buckling force becomes normalized to a $P_{k}=$ $6,955 \mathrm{kN}$, and due to lateral restrains caused by the surrounding soils of the pile, this force is always greater than buckling force of a column (p-p) made of elastic material - the Euler's force $P_{E}=E I \cdot \pi^{2} / L^{2}$.

The diagram of the buckling force $P_{c r}$, depending on the pile length $(L)$, for the case of a pile of stiffness and end conditions, same as of the above mentioned case (p-p) but with the modulus of horizontal subgrade reaction that linearly increases with depth, from nonzero value at the surface, $k_{0}=1,000 \mathrm{kN} / \mathrm{m}^{2}$ and $n_{h}=1,000 \mathrm{kN} / \mathrm{m}^{3}$, are given in Fig. 3. With an increase of the pile length $(L)$, the buckling force of fully embedded pile (p-p), converges to the value $P_{k}=$ $1.432 * 10^{4} \mathrm{kN}$, that is approximately twice greater as the buckling force of the fully embedded pile ( $p-p)$ of a constant modulus of horizontal subgrade reaction in

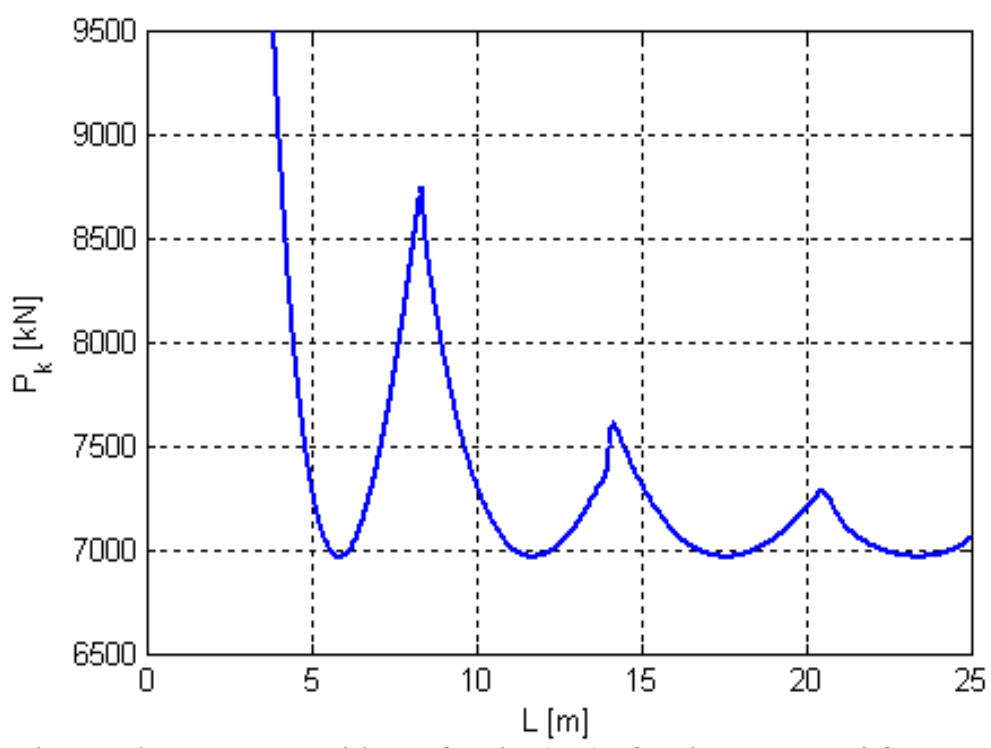

Fig. 2 Buckling force for pinned-pinned end conditions of a pile (p-p) of a diameter $D=0.3 \mathrm{~m}$, concrete class $\mathrm{C25} / 30$, length $L$, and when modulus of horizontal subgrade reaction $k_{0}=1,000 \mathrm{kN} / \mathrm{m}^{2}$ (as obtained by MATLAB). 


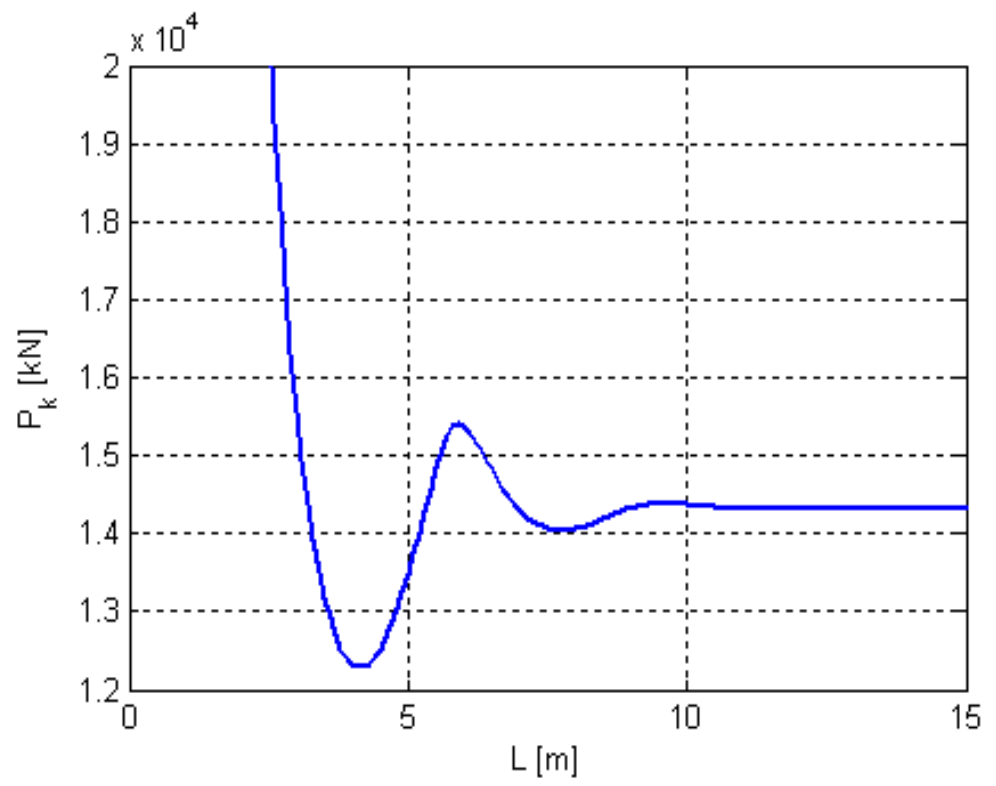

Fig. 3 Buckling force for pinned-pinned end conditions of a pile (p-p), of a diameter $D=0.3 \mathrm{~m}$, concrete class $\mathrm{C25} / 30$, length $L$, and soil stiffness, $k=1,000 \mathrm{kN} / \mathrm{m}^{2}$ and $n_{h}=1,000 \mathrm{kN} / \mathrm{m}^{3}$ (as obtained by MATLAB).

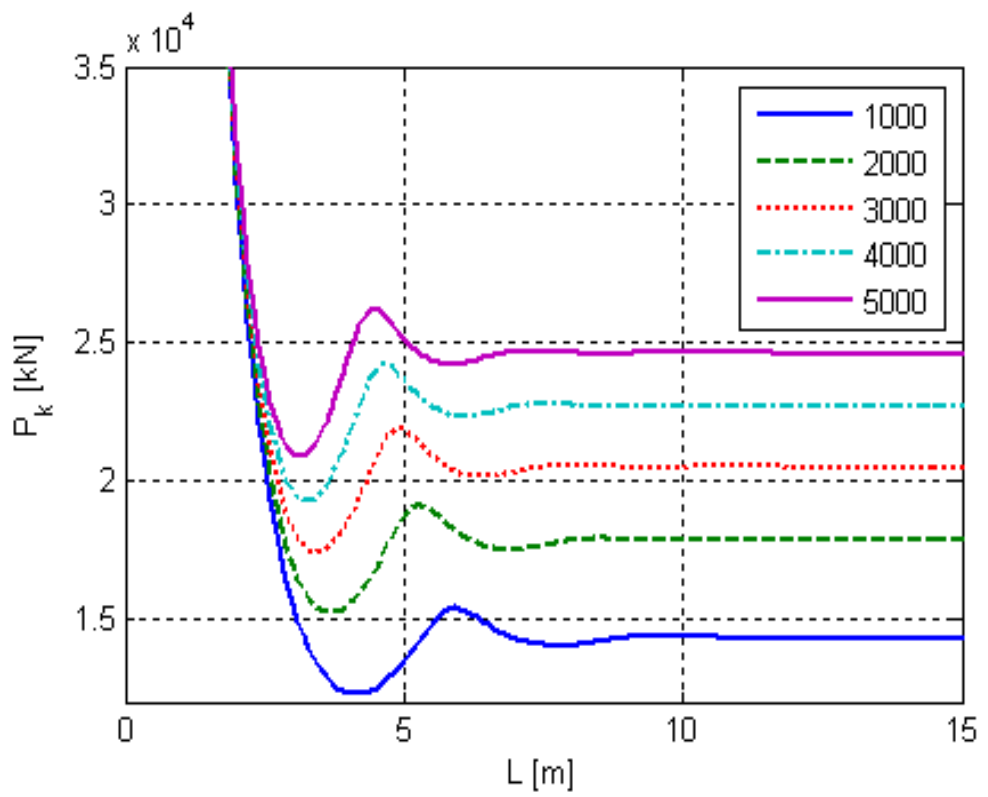

Fig. 4 Buckling forces for a pinned-pinned end conditions of a pile (p-p), of diameter diameter $D=0.3 \mathrm{~m}$, concrete class C25/30, length $L$, when $k_{0}=1,000 \mathrm{kN} / \mathrm{m}^{2}$ and $n_{h}=1,000,2,000,3,000,4,000,5,000 \mathrm{kN} / \mathrm{m}^{3}$ (as obtained by MATLAB).

depth $\left(k_{h}=k_{0}=1,000 \mathrm{kN} / \mathrm{m}^{2}\right.$ and $\left.P_{k}=6,955 \mathrm{kN}\right)$. In this case also, the pile deforms in a mode of a half wave of a sine curve, with a number of waves depending on the total length of the pile.

The effect of increasing " $n_{h}$ " values on a buckling force of the pile (p-p) when " $k_{0}$ " is kept constant, is given in Fig. 4. A fully embedded pile (p-p) in soil of $k_{0}=1,000 \mathrm{kN} / \mathrm{m}^{2}$ and $n_{h}$ different from 1,000 to
$5,000 \mathrm{kN} / \mathrm{m}^{2}$, is adopted for analysis. It is observed in Fig. 4, buckling modes are varying between as the pile length increases, as well as an increase of a buckling force as the $n_{h}$ value increase.

In Fig. 5, through spatial diagrams of buckling forces $P_{k}$ as a function of pile length $L$, the effect of the increase of the values of the modulus of horizontal subgrade reaction, $k_{0}$, is given, on a pile buckling 
force when the constant of horizontal subgrade reaction is kept constant, $\left(n_{h}=\right.$ constant $)$. The constant of horizontal subgrade reaction is adopted $n_{h}=$ $1,000 \mathrm{kN} / \mathrm{m}^{3}$ whereas the modulus of horizontal subgrade reaction " $k_{0}$ " increasing from 1,000 to $5,000 \mathrm{kN} / \mathrm{m}^{2}$.

As in the previous case, buckling load $P_{k}$ increases with an increase of " $k_{0}$ " while " $n_{h}$ " remains constant and the fundamental buckling mode shapes change with an increase of pile length (Figs. 6-9).

Comparing the given diagrams in Fig. 4 with those in Fig. 5, conclusion can be drawn that values of pile buckling forces (p-p), are higher for the cases when $k_{0}$ $=$ constant and $n_{h}$ changing comparing to cases $n_{h}=$ constant and $k_{0}$ changing.

Buckling length of a pile (p-p), diameter $D=0.3 \mathrm{~m}$,

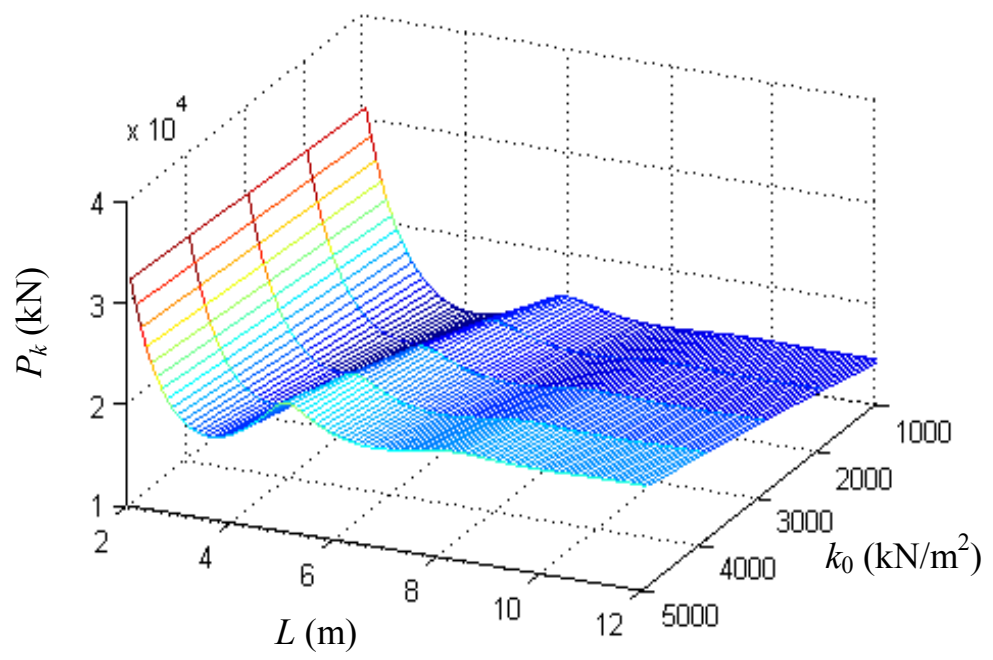

Fig. 5 Buckling forces for a pinned-pinned end conditions of a pile (p-p) of diameter $D=0.3 \mathrm{~m}$, concrete class C25/30, length $L$, when $k_{0}=1,000,2,000,3,000,4,000$ and $5,000 \mathrm{kN} / \mathrm{m}^{3}$ and $n_{h}=1,000 \mathrm{kN} / \mathrm{m}^{3}$ (as obtained by MATLAB).

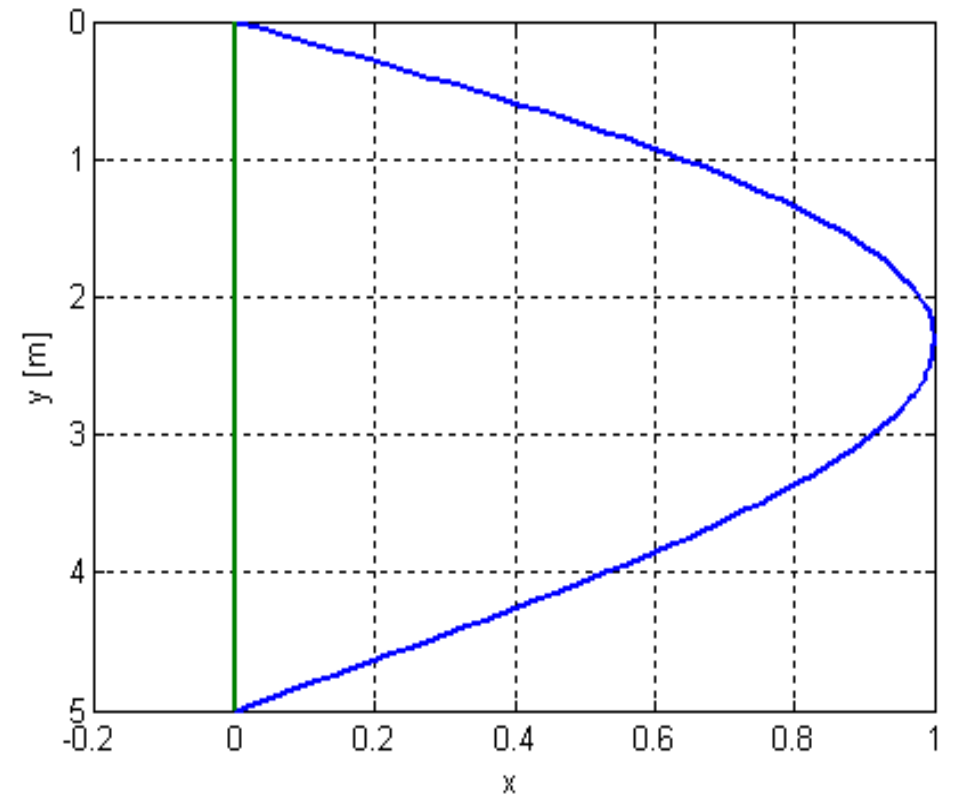

Fig. 6 Fundamental buckling mode shape of the fully embedded pile (p-p), of diameter $D=0.3 \mathrm{~m}$, concrete class $\mathrm{C} 25 / 30$ for $n_{h}=1,000 \mathrm{kN} / \mathrm{m}^{3}$ and pile length $L=5 \mathrm{~m}$ (as obtained by MATLAB). 


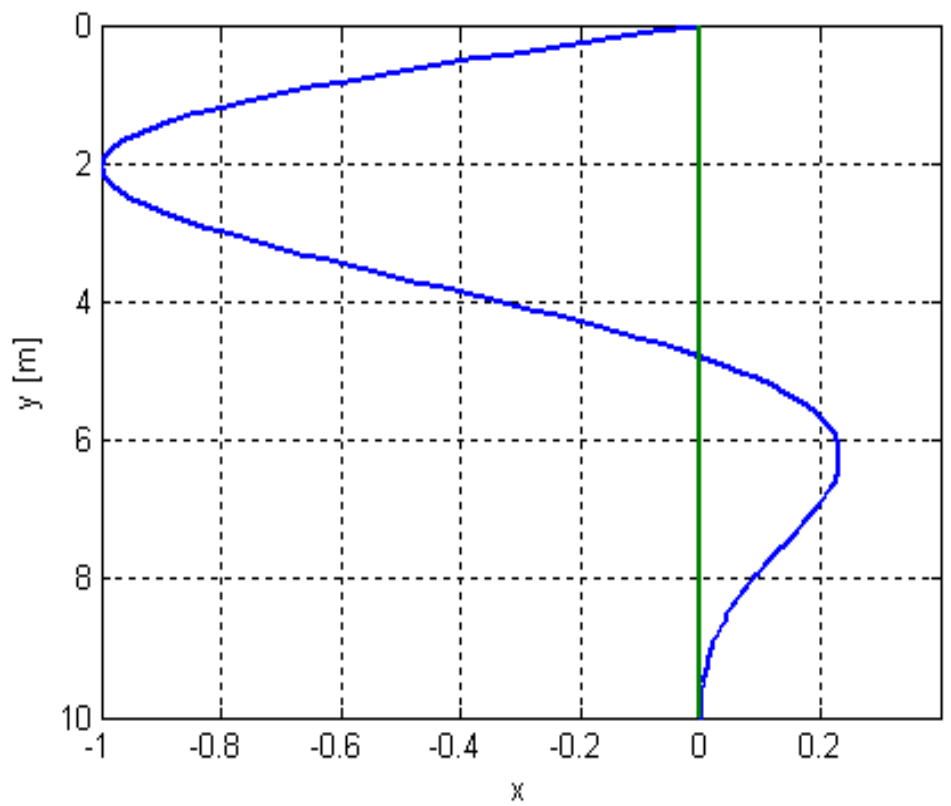

Fig. 7 Fundamental buckling mode shape of the fully embedded pile pinned top-pinned tip, of diameter $D=0.3 \mathrm{~m}$, concrete class C25/30, for $n_{h}=1,000 \mathrm{kN} / \mathrm{m}^{3}$ and $L=10 \mathrm{~m}$ (as obtained with MATLAB).

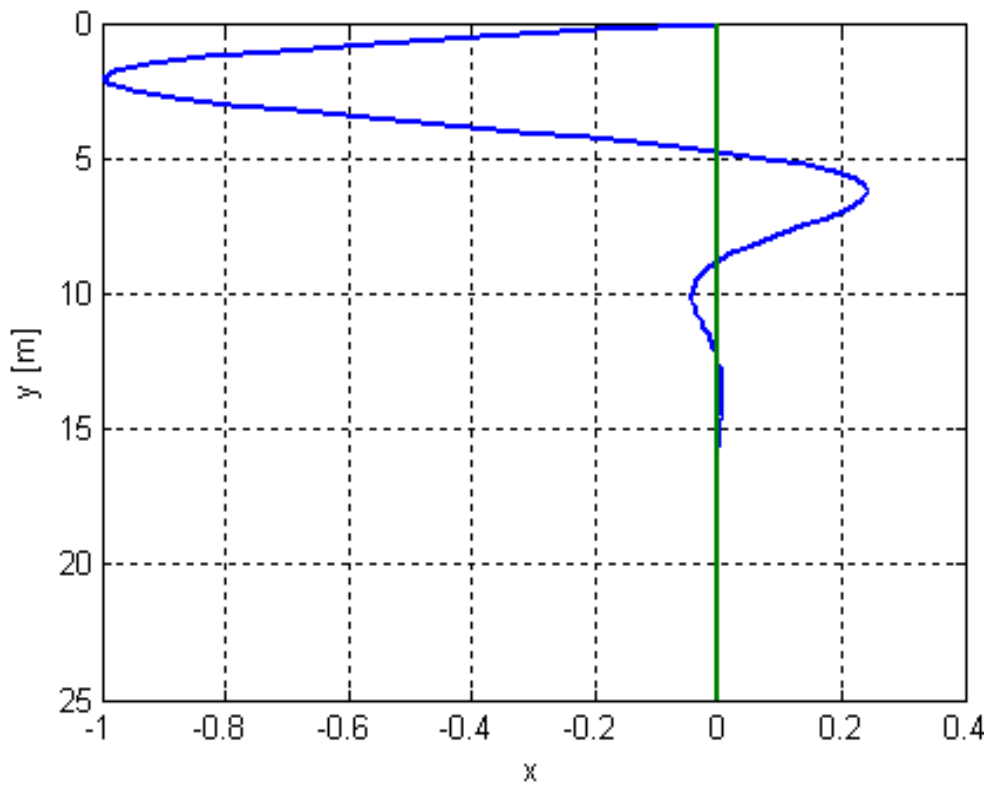

Fig. 8 Fundamental buckling mode shape of the fully embedded pile, pinned top-pinned tip, of diameter $D=0.3 \mathrm{~m}$, concrete class C25/30, for $n_{h}=1,000 \mathrm{kN} / \mathrm{m}^{3}$ and $L=25 \mathrm{~m}$ (as obtained by MATLAB).

length $L=25 \mathrm{~m}$ and concrete class C25/30, is smaller in case when the pile is fully embedded in ground of $k_{0}=1,000 \mathrm{kN} / \mathrm{m}^{2}$ and $n_{h}=25,000 \mathrm{kN} / \mathrm{m}^{3}$ (Fig. 9) than when the same pile is embedded in ground of $k_{0}=$ $0.0 \mathrm{kN} / \mathrm{m}^{2}$ and $n_{h}=1,000 \mathrm{kN} / \mathrm{m}^{3}$ (Fig. 8).

So, as stiffer the soil is, comparing with pile stiffness, the pile buckling length will be relatively smaller.

\section{The Influence of the Boundary Conditions on the Buckling Force}

To show the extent of the influence of the end conditions of a pile into a buckling force, a pile of diameter $D=0.3 \mathrm{~m}$, concrete class C25/30, of length $L$, fully embedded on ground of the constant of horizontal subgrade reaction $n_{h}=200 \mathrm{kN} / \mathrm{m}^{3}$ and the 


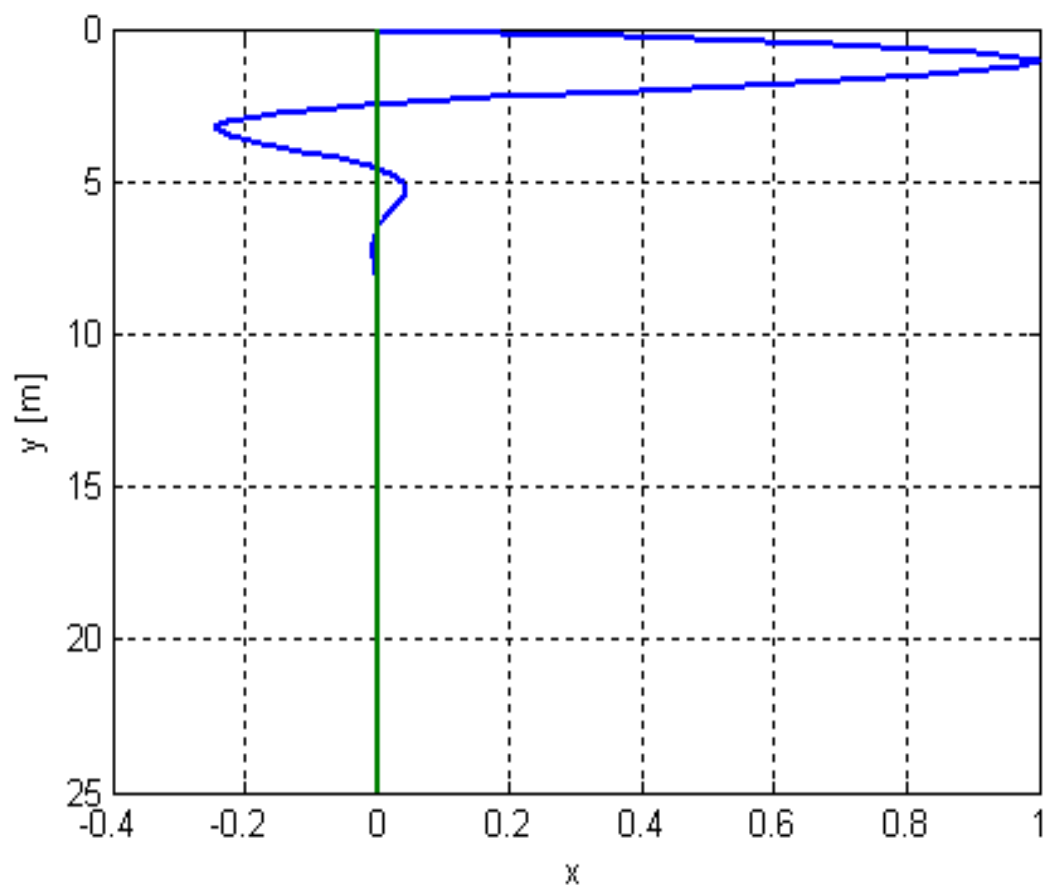

Fig. 9 Fundamental buckling mode shape of the fully embedded pile (p-p) of length $L=25 \mathrm{~m}$, for $k_{0}=1,000 \mathrm{kN} / \mathrm{m}^{2}$ and $n_{h}=$ $25,000 \mathrm{kN} / \mathrm{m}^{3}$ (as obtained by MATLAB).

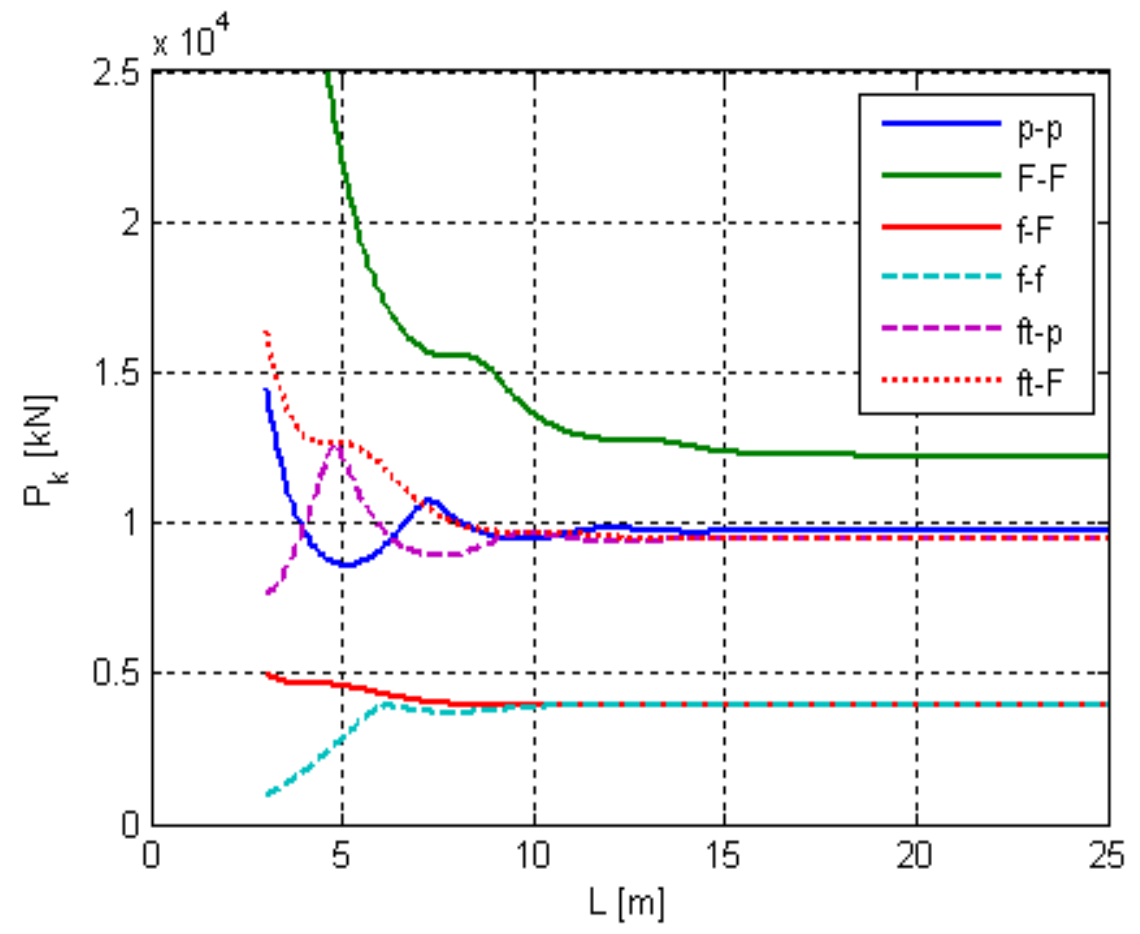

Fig. 10 The influence of end conditions to a buckling forces of a fully embedded pile with diameter $D=0.3 \mathrm{~m}$, concrete class $\mathrm{C25} / 30$, length $L$, for modulus of horizontal subgrade reaction $k_{0}=1,000 \mathrm{kN} / \mathrm{m}^{2}$ and a constant of horizontal subgrade reaction $n_{h}=200 \mathrm{kN} / \mathrm{m}^{3}$ (as obtained by MATLAB).

modulus of horizontal subgrade reaction $k_{0}=$ $1,000 \mathrm{kN} / \mathrm{m}^{3}$, of the end conditions: pinned at the top-pinned at the tip (p-p), fixed at the top-fixed at the tip (F-F), free at the top-fixet at the (f-F), free at 
the top-free at the tip (f- $f$ ), fixed against rotation but free in translation top-pinned at the tip (ft-p), and fixed against rotation but free in translation-fixed at the tip (ft-F), are taken for consideration [2].

Referring to Fig. 10, depending on the values of buckling forces obtained, the piles are clasified into three groups:

(1) the first group - a pile (F-F);

(2) the second group - a pile (p-p), (ft-p) and (ft-F);

(3) the third group - a pile (f-f) and (f-F).

The maximum values of buckling forces are obtained for a pile of the end conditions fixed at the top-fixed at the tip (F-F), while the minimum values are obtained for the piles of the end conditions, (f-f) and (f-F). The buckling forces for piles (p-p, ft-p and $\mathrm{ft}-\mathrm{F}$ ) distinguish for the higher force values comparing to the forces for the piles (f-f and $f-F$ ), and smaller than for piles of end conditions (F-F).

From Fig. 10, the behavior of pile (f-F), length of $L$ $\geq 10 \mathrm{~m}$, is the same as that of the type (f-f) since the buckling forces calculated with MATLAB for these two types of piles, based on the finite difference method, both converge to $P_{k}=0.39 \times 10^{4} \mathrm{kN}$.

For the lengths $L>10 \mathrm{~m}$, for the case of the pile (p-p) (Fig. 10), the buckling force converges to value of $0.97 \times 10^{4}$, while converging to $0.95 \times 10^{4}$ for the case of the piles (ft-p and ft-F). Since the difference in these values of buckling forces is only $2 \%$, these two types of piles may be categorized in the same group.

As seen in Fig. 10, it may be also concluded that there is only the end condition of the head that influences the buckling force and not the end condition of the tip of the pile, as well as that with an increase of the pile length the buckling force of the pile remains unchanged.

\section{Conclusions}

The method for determination of the buckling forces of piles of different restraint conditions based on the method of finite differences is presented in this paper work. The software MATLAB is used to determine the forces by applying this method.

The pile buckling forces depend on the pile length $L$, on the pile stiffness $E I$, boundary conditions and on the geometric properties of soils. They increase with an increase of constant of horizontal subgrade reaction $n_{h}$, by keeping constant the modulus of horizontal subgrade reaction $k_{h}$, as well as in contrary, when modulus of horizontal subgrade reaction $k_{h}$ is increased, while the constant of horizontal subgrade reaction $n_{h}$ remains constant. For the case of piles of end conditions pinned at top-pinned at tip ( $p-p)$, higher values of buckling forces are obtained in cases when the constant of soil reaction $n_{h}$ increases while the modulus of soil reaction $k_{h}$ is kept unchanging.

The buckling force is maximal for the pile of the end conditions fixed-fixed (F-F) due to the increase of the restraint that offered by the fixed top and the fixed tip, and the force is minimal for the end conditions free-free (f-f) and free-fixed (f-F).

In the value of buckling force of a pile, only the end condition of the head of the pile is prevailing.

With an increase of the pile length, the buckling force remains unchanged.

The modal shapes of buckling of piles analysed with MATLAB software are influenced by pile length since they differ between with an increase of the length of the pile. The buckling mode changes from the first mode to the second and then to the third as the length of the pile increases.

\section{References}

[1] Terzaghi, K. 1955. "Evaluation of Coefficients of Subgrade Reactions." Geotechnique 5 (4): 41-50.

[2] Poulos, H. G., and Davis, E. H. 1980. Pile Foundation Analysis and Design. New York: Wiley.

[3] Reese, L. C., and Wang, S. T. 2006. Verification of Computer Program Lpile as a Valid Tool for Design of a Single Pile under Lateral Loading. Technical Manual. Ensoft, Inc.

[4] Wai, L. C. 2013. "Parametric Studies on Buckling of Piles in Cohesionless Soils by Numerical Methods." Hkie Transactions 20 (1): 12-33.

[5] Wen-pei, S., Ming-hsiang, S., Cheng-I, L., and Germ, G. 
C. 2005. "The Critical Loading for Lateral Buckling of Continuous Welded Rail.” Journal of Zhejiang University Science A 6 (8): 878-85. DOI: 10.1631/jzus.2005A087.
[6] Prakash, S., and Sharma, D. H. 1990. Pile Foundations in Engineering Practice. New York: Jon Wiley and Sons, Inc. 